\title{
Viability and collagen secretion by fibroblasts on titanium surfaces with different acid-etching protocols
}

\author{
Vilton Zimmermann de Souza ${ }^{1}$, Rafael Manfro², Júlio César Joly ${ }^{1}$, Carlos Nelson Elias ${ }^{3}$, Daiane Cristina Peruzzo ${ }^{1}$, \\ Marcelo Henrique Napimoga ${ }^{4}$ and Elizabeth Ferreira Martinez ${ }^{5^{*}}$ (D)
}

\begin{abstract}
Background: From the consolidation of surface treatments of dental implants and knowledge on the cellular mechanisms of osseointegration, studies have highlighted the importance of a connective tissue seal against the implant to prevent contamination from the oral environment and consequent biofilm formation.

Objective: This in vitro study aimed to evaluate whether different titanium surface treatments using acid solutions promoted an increase in collagen secretion, proliferation, and viability of fibroblasts.

Material and methods: Commercially pure grade-4 titanium disks $(6 \times 2 \mathrm{~mm})$ were treated with different acid solutions (hydrochloric, nitric, and sulfuric) for 20 and $60 \mathrm{~min}$, respectively, obtaining mean surface roughness of 0.1 to $0.15 \mu \mathrm{m}$ and 0.5 to $0.7 \mu \mathrm{m}$. Human fibroblasts were seeded onto different surfaces and assessed after $24 \mathrm{~h}, 48 \mathrm{~h}$, and $72 \mathrm{~h}$ for cell proliferation and viability using Trypan blue staining and MTT, respectively, as well as the secretion of type I collagen on to such surfaces using ELISA. Machined titanium surfaces were used as controls. Data were statistically analyzed using one-way ANOVA and Fisher's LSD test for multiple comparisons, adopting a significance level of $5 \%$.
\end{abstract}

Results: No significant difference was observed in cell proliferation for the different surfaces analyzed. Cell viability was significantly lower on the machined surface, after $48 \mathrm{~h}$, when compared to the groups treated with acid for 20 or $60 \mathrm{~min}$, which did not differ from each other. The expression of type I collagen was lowest on the acid-treated surfaces.

Conclusion: The results showed that the acid treatment proposed did not promote fibroblast proliferation and viability nor favor type I collagen synthesis.

Keywords: Surface treatment, Dental implant, Connective tissue

\section{Introduction}

Consolidation of surface treatments for dental implants and knowledge on the cellular mechanisms of osseointegration has propelled research on the sealing capacity of bone to implant surfaces. Although osseointegration is extremely important for implant success, biological sealing of the perimplantar connective tissue is crucial to maintain success in

\footnotetext{
* Correspondence: dr.efmartinez@gmail.com;

elizabeth.martinez@sImandic.edu.br

${ }^{5}$ Division of Oral Biology and Cell Biology, Faculdade São Leopoldo Mandic,

Rua José Rocha Junqueira, 13, Campinas, SP 13045-755, Brazil

Full list of author information is available at the end of the article
}

the long-term because it acts as a first barrier to epithelial migration [1].

Collagen fibers from the band of connective tissue adjacent to the junctional epithelium, which would be directed perpendicularly to the tooth surface, are directed parallel to the long axis of the implant, forming a beltlike structure around the cervical portion of the implant [2-4]. Therefore, no connective tissue fiber attachment is established with the implants, but only direct contact of fibroblasts from this region with the titanium surface, which together with low vascularization favors bacterial penetration $[3,5,6]$. 
There is no consensus in the literature as to whether surface treatment of prosthetic abutments promotes increased fibroblast proliferation and adhesion. Some studies have shown, however, that topographic modifications to the surface of prosthetic abutments maybe beneficial to the connective tissue adjacent to the abutments, optimizing repair of the gingival tissues [7-11]. Nanotopography and macrogeometry may influence cell adhesion and behavior, which may contribute to such findings.

Considering the importance of a marginal seal for the health and quality of the perimplant tissues, understanding fibroblast behavior on different surface features is fundamental to control the progression of perimplant disease, tissue stabilization, and esthetics. Therefore, the aim of this study was to evaluate the effect of titanium surface treatment using different acid etching time schedules on the morphology, proliferation, and viability, as well as collagen synthesis by gingival fibroblasts.

\section{Material and methods}

This study was approved by the Research Ethics Committee of the São Leopoldo Mandic Research Institute, Campinas/SP (protocol No. 59866216.6.0000.5374). Titanium disks were commercially pure, grade $4(n=108)$, measuring $6 \mathrm{~mm}$ in diameter by $2 \mathrm{~mm}$ in thickness, provided by the company Conexão Sistemas de Próteses (Arujá, São Paulo).

For the treatment of titanium disk surfaces, sulfuric, nitric, and hydrochloric acid solutions were used for 20 $\min (n=36)$ and $60 \min (n=36)$. As a control, disks with no surface treatment $(n=36$, machined surface only) were used. The concentration of each acid in the solutions is not described because the company did not wish to disclose it. Roughness was measured using a contact profilometer (Mitutoyo, Surftest model SJ200, Brazil, Suzano). Four linear measurements were performed on each sample according to DIN ISO 1302 standard, and the arithmetic mean of the absolute values for each disk ( $\mathrm{Ra}$ ) was calculated. The average roughness (Ra) obtained was 0.1 to $0.15 \mu \mathrm{m}$, for $20 \mathrm{~min}$ of acid treatment, and 0.5 to $0.7 \mu \mathrm{m}$, for $60 \mathrm{~min}$ of acid treatment. Figure 1 shows the morphological characteristics of the surfaces obtained.

The disks were sterilized in ethylene oxide (Acecil, Campinas, São Paulo) and used for the subsequent experiments. Three different human fibroblast cell lines were obtained from the Cell Bank of the Cell Culture Laboratory (São Leopoldo Mandic Research Institute, Campinas) to control for phenotypic and genotypic variations. These cells were previously isolated by primary culture of human gingiva from three patients [12].

\section{Cell proliferation and viability assays}

The cells were cultured on 96-well plates (Corning, NY, USA) at an initial concentration of 110 cells $/ \mathrm{mm}^{2}$. For the cell proliferation assay, the fibroblasts were detached using $0.05 \%$ trypsin and counted on a hemocytometer to calculate proliferation indices at $24 \mathrm{~h}, 48 \mathrm{~h}$, and $72 \mathrm{~h}$. Cell
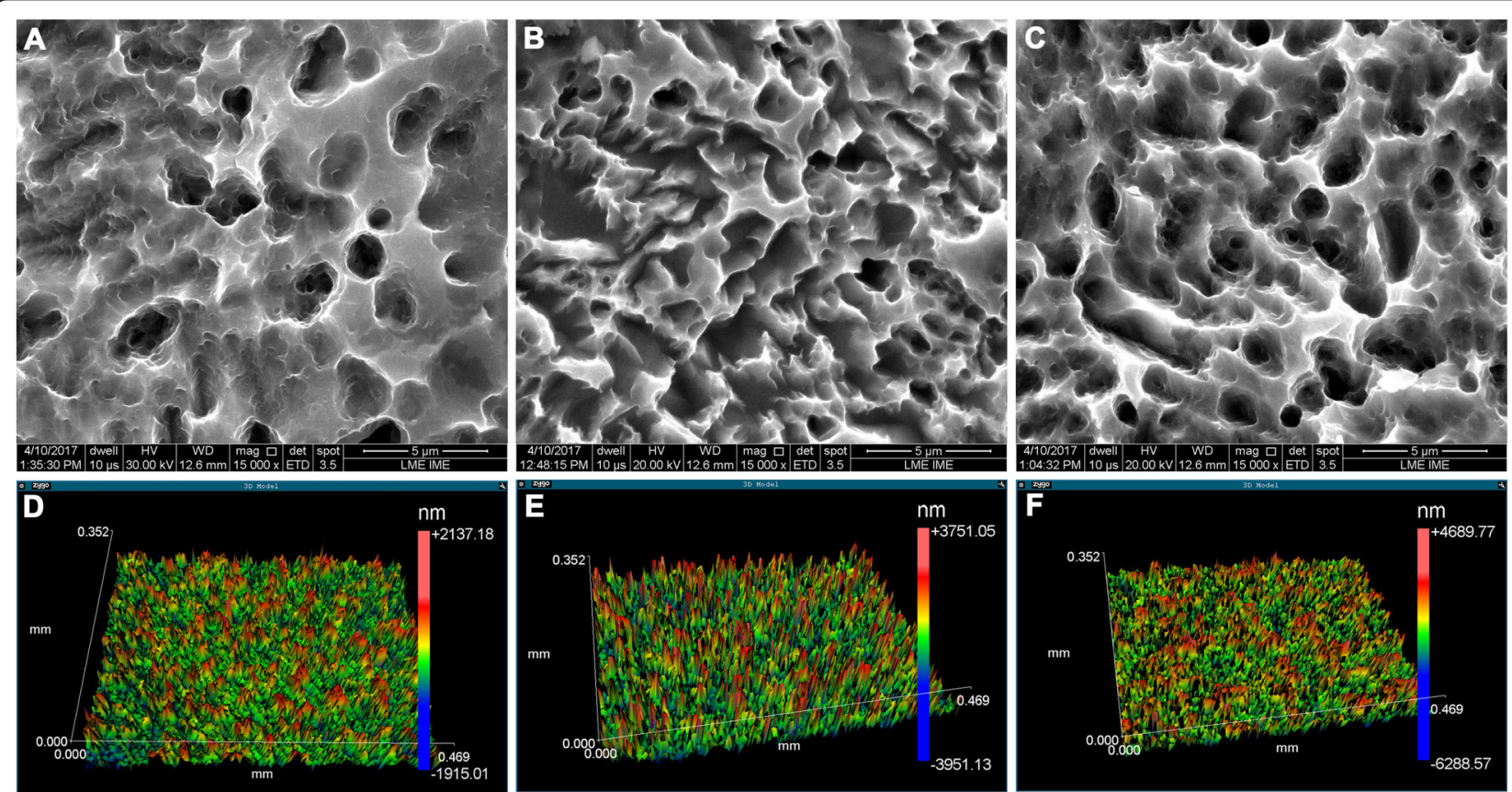

Fig. 1 Scanning electron microscopy and laser interferometry. a, d Machined surface. b, e 20-min acid treatment. c, f 60-min acid treatment. Original magnification, $\times 15,000$ 
viability assay was evaluated by 3-[4,5-dimethylthiazol-2yl]-2,5-diphenyl tetrazolium bromide (MTT, Sigma), at the same time periods. The optical density was read at $570-650 \mathrm{~nm}$ on a plate reader (Epoch, Bio-Tek, Winooski, VT), and data were expressed as absorbance.

The experiments were repeated three times, under the same conditions, to ensure accuracy.

\section{Type I collagen quantification (ELISA)}

Quantification of secreted type I collagen by fibroblast cultures on to the different surfaces was evaluated by enzyme-linked immunosorbent assay (ELISA). The supernatant was collected and centrifuged at $336 g$ for $10 \mathrm{~min}$. Type I collagen quantification was carried out using the Human Type I Collagen kit (R\&D Systems, Minneapolis, USA) according to the manufacturer's instructions. The values were expressed as picogram per milliliter. All the experiments were carried out in triplicate.

\section{Statistical analysis}

To investigate whether acid treatment time had an influence on cell proliferation and viability and type I collagen expression after $24 \mathrm{~h}, 48 \mathrm{~h}$, and $72 \mathrm{~h}$ of culture, oneway ANOVA analysis was applied. Fisher's LSD test was used for multiple comparisons. Statistical calculations were conducted in the SPSS 23 program (SPSS INC., Chicago, IL, USA), adopting a significance level of $5 \%$.

\section{Results}

The results showed that acid treatment of the titanium surfaces for 20 or $60 \mathrm{~min}$ did not affect cell proliferation, either after 24 h $(p=0.484), 48$ h ( $p=0.698)$, or 72 h ( $p=0.287)$ (Fig. 2a).
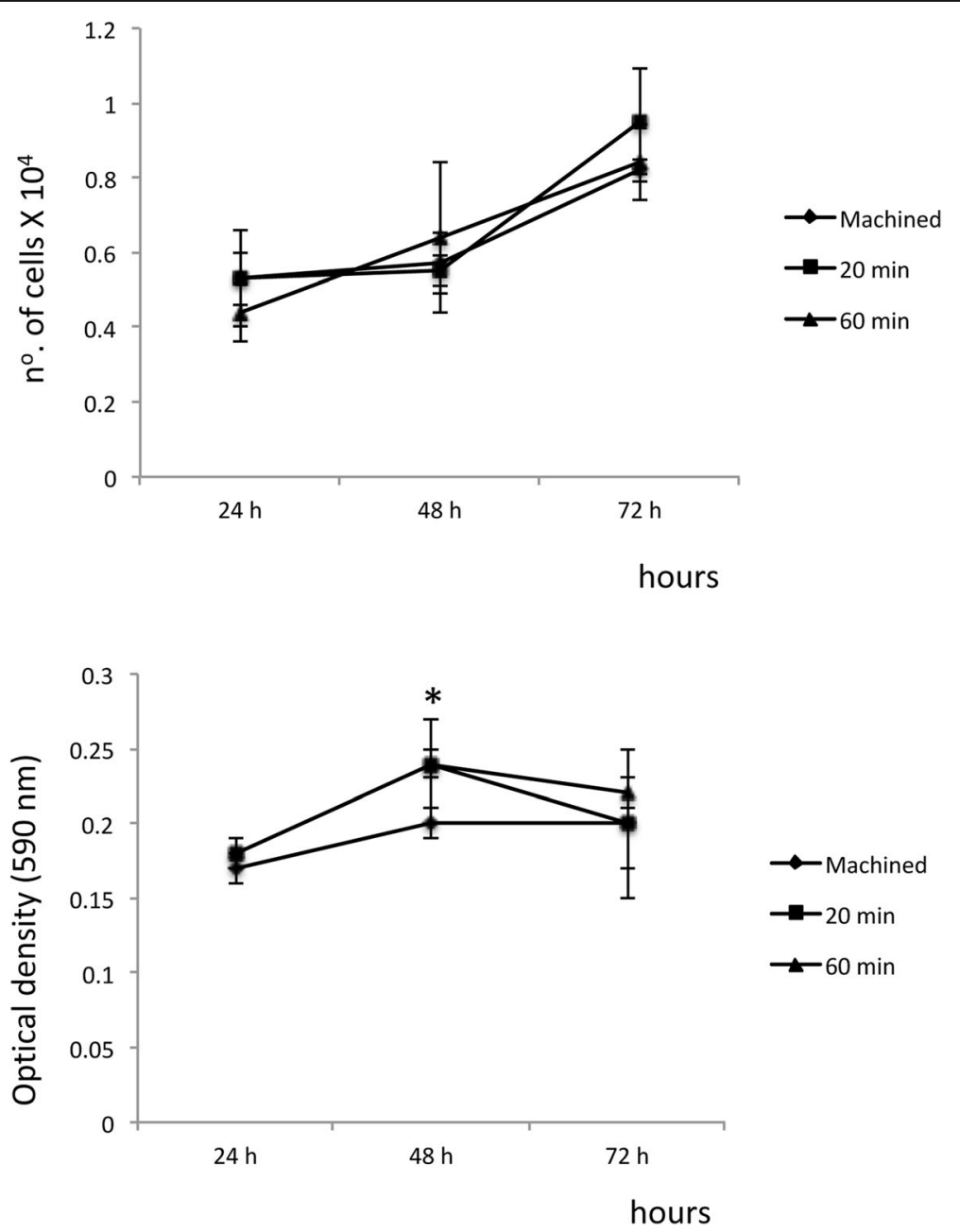

Fig. 2 a Cell proliferation in gingival fibroblasts at $24 h, 48 h$, and $72 \mathrm{~h}$. The line chart represents the means and standard deviations from three separate experiments. $\mathbf{b}$ Cell viability assay in gingival fibroblast at $24 \mathrm{~h}, 48 \mathrm{~h}$, and $72 \mathrm{~h}$. The line chart represents the means and standard deviations from three separate experiments. The values are expressed in means $( \pm \mathrm{SD})$. The asterisk symbol indicates a significant difference between groups $(p<0.05)$ 
For the cell viability test, loss of viability was observed for the machined surface after $48 \mathrm{~h}$ of culture compared to the groups submitted to acid treatment for 20 or 60 min, which did not differ statistically between each other (Fig. 2b). No significant difference between groups regarding cell viability was verified after $24 \mathrm{~h}(p=0.590)$ and $72 \mathrm{~h}(p=0.799)$.

As for type I collagen synthesis, the lowest yields were observed on acid-treated surfaces, regardless of the application times (20 min or $60 \mathrm{~min}$ ) after $48 \mathrm{~h}$ (Fig. 3). One-way ANOVA showed no significant difference between the groups regarding the expression of type I collagen at $24 \mathrm{~h}$ and $72 \mathrm{~h}$.

\section{Discussion}

Implant dentistry has for years focused on studying the interface between the bone and implant, searching for a suitable seal to prevent the advance of perimplant disease. Long-term prognosis of dental implants, however, depends not only on osseointegration, but also on the quality of the seal between the mucosa and the implant abutment [13].

The seal provided by the contact between mucosal tissue and the prosthetic abutment seems to be the safest route to implant longevity and long-term tissue stability. Currently, prosthetic abutments have their transmucosal collars manufactured with machined and polished surfaces. In the search for a titanium surface that favors cellular events, this study aimed to analyze if titanium surfaces treated with acid solution for different lengths of time could alter the behavior of fibroblasts, seeking a more stable union and promoting a better seal for perimplant health than otherwise polished surfaces.

The results of the present study showed that, in general, different acid treatment times did not increase the cellular events evaluated, namely cell proliferation, viability, and type I collagen secretion.

Some studies have reported that gingival fibroblasts seeded onto treated surfaces show greater proliferation and cellular viability when compared to machined surfaces $[8,9]$, indicating an advantage to treating the prosthetic abutment or the cervical portion of the implant to enhance a biological seal. It is important to highlight from the literature that cell type and cell cycle phase as well as surface type and chemical composition of the material may differ, which may in turn generate different results.

In spite of the numerous current options for prosthetic abutment materials given the high esthetic demand, titanium was used in the present study, which is a widely cited material in the literature as the gold standard when used as a prosthetic abutment, due to its high biocompatibility [14, 15]. Thus, the effect of applying an acid treatment protocol, which is widely used for dental implant surface treatment, on the proliferation, synthesis, and secretion of collagen by gingival fibroblasts was studied. The results obtained from the acid treatments allowed for smooth and minimally rough surfaces, according to the criteria adopted by Albrektsson and Wennergerg [16], respectively, for the acid treatments after $20 \mathrm{~min}$ and $60 \mathrm{~min}$. This indicates that, despite acid treatment, 20 min was not sufficient to create surface roughness on the titanium surface with the acid solutions used.

The results showed that, regardless of the treatment used, there was no difference in the values of cell proliferation in the different times of analysis. Similarly, cell

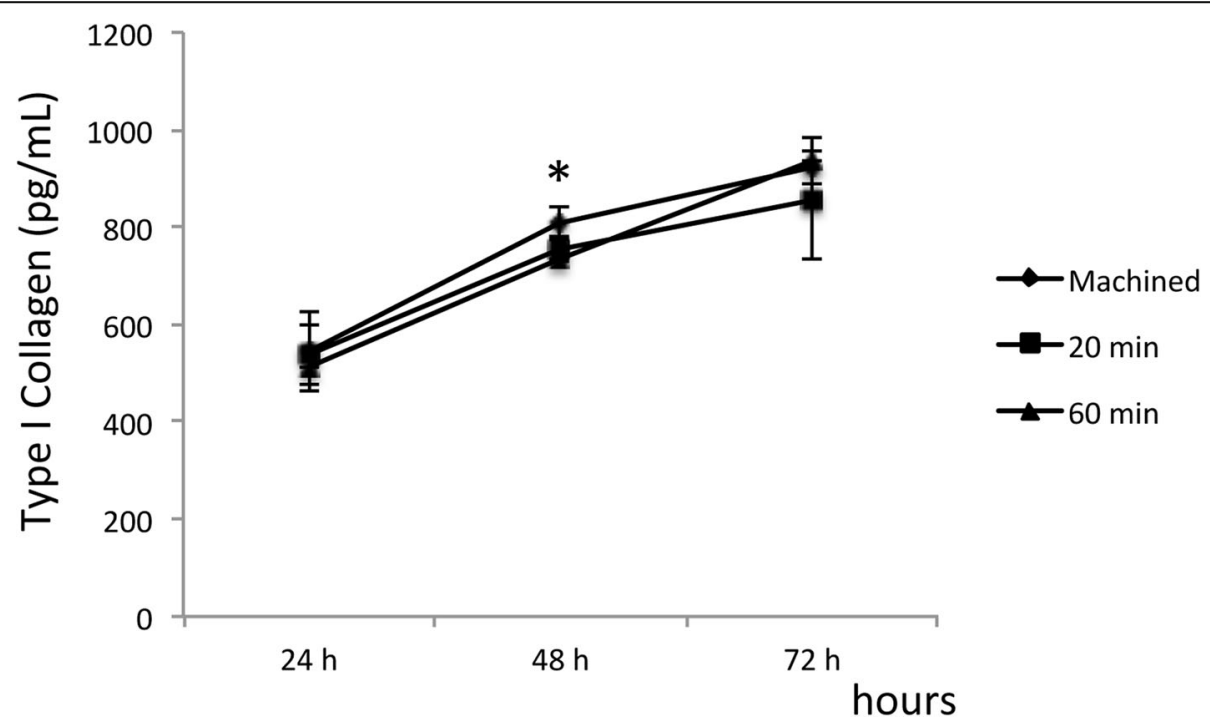

Fig. 3 Quantification of type I collagen via ELISA. Data representative of the experiment run in triplicate. Values are expressed as mean ( \pm SD). The asterisk symbol indicates a significant difference between groups $(p<0.05)$ 
viability values did not differ, especially after $24 \mathrm{~h}$ and $72 \mathrm{~h}$. Corroborating the results of this study, Baltriukiene et al. [17] used grade 2 titanium disks with different surface treatments and demonstrated that the modified titanium surface did not affect human gingival fibroblast viability. Interestingly, some studies show that smooth surfaces increase the proliferation and adhesion of fibroblasts $[18,19]$, which raises the question of whether the recommended acid treatment of titanium surfaces indeed has an advantage in terms of promoting greater biological sealing. In addition, increased surface roughness promotes bacterial colonization and increased retention [20, 21], contributing to increased biofilm formation.

In the present study, human gingival fibroblasts were used in a similar strategy as per other reports in the literature [10, 15, 22-25]. In spite of in vivo studies representing the ideal environment to investigate tissue responses, in vitro studies facilitate the investigation of a specific and isolated factor of the tissue response [26]. In addition to being widely used in cell biocompatibility studies, considering the various topographic surface features, fibroblasts are responsible for the biosynthesis of collagen and other extracellular matrix molecules.

To establish the amount of protein secreted by fibroblasts, we chose type I collagen, as it is the most abundant protein in the extracellular matrix of gingival connective tissue, representing almost $90 \%$ of the total organic matrix in mature bone. The results revealed differences between groups only at $48 \mathrm{~h}$ of culture, where the lowest titers were observed when surfaces were treated with acid solutions. At $24 \mathrm{~h}$ and $72 \mathrm{~h}$, no significant difference was observed regarding collagen secretion, though the highest quantification occurred at $72 \mathrm{~h}$ for the surfaces treated for $60 \mathrm{~min}$. These results are in agreement with the findings by Ramaglia et al. [9] and Velasco-Ortega et al. [24], in which they suggested that roughened surfaces may improve the biological behavior of fibroblasts as well as the process of perimplant soft tissue healing and osseointegration compared to machined surfaces.

The connective tissue seal around the abutment is crucial for perimplant health. Several efforts have previously been made to optimize abutment surfaces, though without consensus on the ideal surface features. Blasquez et al. [11] have shown in their systematic review that different types of surface modifications for implant abutments may provide benefit to the surrounding connective tissue, which generally corroborate the results reported herein. It is noteworthy that different methodologies and cell types, together with different types of acid solutions, might lead to different outcomes compared to the present study.

Cao et al. [25] with the aim of investigating the effects of different decontamination treatments on the microstructure of titanium surfaces as well as the proliferation and adhesion of human gingival fibroblasts showed that proliferation and adhesive strength were higher in the machined surfaces than on treated surfaces. These results led the group to conclude that proliferation and adhesion increases as surface roughness decreases.

\section{Conclusions}

Therefore, the results of the present study indicate that the acid treatments used did not compromise cell growth nor collagen synthesis by gingival fibroblasts compared to machined titanium. The cost-benefit of manufacturing prosthetic abutments with treated surfaces should however be considered. In addition, in vitro studies using human keratinocytes and histological studies in vivo should be performed to identify the profile and direction of the fibers associated to these surfaces, which may shed a light on whether the appropriate perimplant biological seal actually occurs. The literature shows a lack of conclusive studies on this subject, so further work is needed to reach an ideal surface for prosthetic components over implants, promoting perimplant connective tissue health based on tissue adhesion and, consequently, a better seal between soft tissue and prosthetic component.

\section{Acknowledgements \\ The authors wish to thank Mrs. Pollyanna Tombini Montaldi for her excellent technical expertise and assistance. \\ Authors' contributions \\ VZS and EFM interpreted and analyzed the data collected, contributed to the drafting of the paper and revised it critically, and were major contributors in writing the manuscript. RM, JCJ, and CNE contributed to the concept/design of the study and the final manuscript. DCP and MHN critically revised and contributed to the final manuscript. All authors read and approved the final version to be published.}

\section{Funding}

The funding received for this study was from the researcher himself.

\section{Availability of data and materials}

All data generated or analyzed during this study are included in this published article.

Ethics approval and consent to participate

This study was approved by the Research Ethics Committee of the São Leopoldo Mandic Research Institute, Campinas/SP (protocol No.

59866216.6.0000.5374)

\section{Consent for publication}

Not applicable.

\section{Competing interests}

Vilton Zimmermann de Souza, Rafael Manfro, Júlio César Joly, Carlos Nelson Elias, Daiane Cristina Peruzzo, Marcelo Henrique Napimoga, and Elizabeth Ferreira Martinez state that they have no conflicts of interest.

\section{Author details}

'Division of Implantology, Faculdade São Leopoldo Mandic, Campinas, SP, Brazil. '2Division of Implantology, SOEBRÁS, Passo Fundo, RS, Brazil. ${ }^{3}$ Materials Science Department, Instituto Militar de Engenharia, Rio de Janeiro, RJ, Brazil. ${ }^{4}$ Division of Immunology, Faculdade São Leopoldo Mandic, Campinas, SP, 
Brazil. ${ }^{5}$ Division of Oral Biology and Cell Biology, Faculdade São Leopoldo Mandic, Rua José Rocha Junqueira, 13, Campinas, SP 13045-755, Brazil.

Received: 9 August 2019 Accepted: 24 October 2019

Published online: 21 November 2019

\section{References}

1. Chai WL, Moharamzadeh K, Brook IM, Van Noort R. A review of histomorphometric analysis techniques for assessing implant-soft tissue interface. Biotech Histochem. 2011;86(4):242-54.

2. Buser D, Weber HP, Donath K, Fiorellini JP, Paquette DW, Williams RC. Soft tissue reactions to non-submerged unloaded titanium implants in beagle dogs. J Periodontol. 1992:63(3):225-35.

3. Schierano G, Ramieri G, Cortese M, Aimetti M, Preti G. Organization of the connective tissue barrier around long-term loaded implant abutments in man. Clin Oral Implants Res. 2002;13(5):460-4.

4. Zitzmann NU, Abrahamsson I, Berglundh T, Lindhe J. Soft tissue reactions to plaque formation at implant abutments with different surface topography. An experimental study in dogs. J Clin Periodontol. 2002;29(5):456-61.

5. Atsuta I, Ayukawa Y, Kondo R, Oshiro W, Matsuura Y, Furuhashi A, Tsukiyama Y, Koyano K. Soft tissue sealing around dental implants based on histological interpretation. J Prosthodont Res. 2016;60(1):3-11.

6. Tzach-Nahman R, Nashef R, Fleissig O, Palmon A, Shapira L, Wilensky A, Nussbaum G. Oral fibroblasts modulate the macrophage response to bacterial challenge. Sci Rep. 2017;7(1):11516.

7. Dorkhan M, Yücel-Lindberg T, Hall J, Svensäter G, Davies JR. Adherence of human oral keratinocytes and gingival fibroblasts to nano-structured titanium surfaces. BMC Oral Health. 201421;14:75.

8. Xing R, Salou L, Taxt-Lamolle S, Reseland JE, Lyngstadaas SP, Haugen HJ. Surface hydride on titanium by cathodic polarization promotes human gingival fibroblast growth. J Biomed Mater Res A. 2014;102(5):1389-98,

9. Ramaglia L, Di Spigna G, Capece G, Sbordone C, Salzano S, Postiglione L. Differentiation, apoptosis, and GM-CSF receptor expression of human gingival fibroblasts on a titanium surface treated by a dual acid-etched procedure. Clin Oral Investig. 2015;19(9):2245-53.

10. Wang $Y$, Zhang $Y$, Jing D, Shuang $Y$, Miron RJ. Enamel matrix derivative improves gingival fibroblast cell behavior cultured on titanium surfaces. Clin Oral Investig. 2016;20(4):685-95

11. Blázquez-Hinarejos M, Ayuso-Montero R, Jané-Salas E, López-López J. Influence of surface modified dental implant abutments on connective tissue attachment: a systematic review. Arch Oral Biol. 2017;80:185-92.

12. Martinez EF, Araújo VC. In vitro immunoexpression of extracellular matrix proteins in dental pulpal and gingival human fibroblasts. Int Endod J. 2004; 37(11):749-55

13. Lee HJ, Lee J, Lee JT, Hong JS, Lim BS, Park HJ, Kim YK, Kim TI. Microgrooves on titanium surface affect peri-implant cell adhesion and soft tissue sealing; an in vitro and in vivo study. J Periodontal Implant Sci. 2015;45(3):120-6.

14. Choi BH. Periodontal ligament formation around titanium implants using cultured periodontal ligament cells: a pilot study. Int J Oral Maxillofac Implants. 2000;15(2):193-6.

15. Grenade C, De Pauw-Gillet MC, Gailly P, Vanheusden A, Mainjot A. Biocompatibility of polymer-infiltrated-ceramic-network (PICN) materials with human gingival fibroblasts (HGFs). Dent Mater. 2016;32(9):1152-64.

16. Albrektsson T, Wennerberg A. Oral implant surfaces: Part 1--review focusing on topographic and chemical properties of different surfaces and in vivo responses to them. Int J Prosthodont. 2004;17(5):536-43.

17. Baltriukiené $D$, Sabaliauskas $V$, Balčiūnas $E$, Melninkaitis A, Liutkevičius $E$, Bukelskienè $V$, Rutkūnas $V$. The effect of laser-treated titanium surface on human gingival fibroblast behavior. J Biomed Mater Res A. 2014; 102(3):713-20

18. Baharloo $B$, Textor $M$, Brunette DM. Substratum roughness alters the growth, area, and focal adhesions of epithelial cells, and their proximity to titanium surfaces. J Biomed Mater Res A. 2005;74(1):12-22.

19. Brunot C, Grosgogeat B, Picart C, Lagneau C, Jaffrezic-Renault N, Ponsonnet L. Response of fibroblast activity and polyelectrolyte multilayer films coating titanium. Dent Mater. 2008:24(8):1025-35.

20. Abrahamsson I, Berglundh T. Effects of different implant surfaces and designs on marginal bone-level alterations: a review. Clin Oral Implants Res. 2009;20 Suppl 4:207-215

21. Wennerberg A, Albrektsson T. On implant surfaces: a review of current knowledge and opinions. Int J Oral Maxillofac Implants. 2010;25(1):63-74.
22. Esfahanizadeh N, Motalebi S, Daneshparvar N, Akhoundi N, Bonakdar S. Morphology, proliferation, and gene expression of gingival fibroblasts on Laser-Lok, titanium, and zirconia surfaces. Lasers Med Sci. 2016;31(5):863-73.

23. Lee DW, Kim JG, Kim MK, Ansari S, Moshaverinia A, Choi SH, Ryu JJ. Effect of laser-dimpled titanium surfaces on attachment of epithelial-like cells and fibroblasts. J Adv Prosthodont. 2015;7(2):138-45.

24. Velasco-Ortega E, Alfonso-Rodríguez CA, Monsalve-Guil L, España-López A Jiménez-Guerra A, Garzón I, Alaminos M, Gil FJ. Relevant aspects in the surface properties in titanium dental implants for the cellular viability. Mater Sci Eng C Mater Biol Appl. 2016;64:1-10.

25. Cao J, Wang T, Pu Y, Tang Z, Meng H. Influence on proliferation and adhesion of human gingival fibroblasts from different titanium surface decontamination treatments: an in vitro study. Arch Oral Biol. 2018;87:204-10.

26. Al Rezk F, Trimpou G, Lauer HC, Weigl P, Krockow N. Response of soft tissue to different abutment materials with different surface topographies: a review of the literature. Gen Dent. 2018;66(1):18-25.

\section{Publisher's Note}

Springer Nature remains neutral with regard to jurisdictional claims in published maps and institutional affiliations.

\section{Submit your manuscript to a SpringerOpen ${ }^{\circ}$ journal and benefit from:}

- Convenient online submission

- Rigorous peer review

- Open access: articles freely available online

- High visibility within the field

- Retaining the copyright to your article

Submit your next manuscript at $>$ springeropen.com 